\title{
PENGARUH MODEL COOPERATIVE TERPADU DALAM PEMBELAJARAN MEMAHAMI IDE POKOK PADA TEKS EKSPLANASI SISWA KELAS XI IPS 1 DI SMA NEGERI 1 SUNGAILIAT KABUPATEN BANGKA
}

\author{
Juaidah Agustina, Heny Maulana \\ (Dosen, Mahasiswa Universitas PGRI Palembang)
}

\begin{abstract}
ABSTRAK
Pembelajaran cooperative terpadu memungkinkan setiap kelompok untuk saling bekerjasama dengan kelompok lain, setiap kelompok mempresentasikan hasil diskusinya dan kelompok lain menghargai dengan baik kepada kelompok yang mempresentasikan hasil belajarnya. Rumusan masalah dalam penelitian ini adalah adakah pengaruh model cooperative terpadu dalam pembelajaran memahami ide pokok pada teks eksplanasi siswa kelas XI IPS 1 di SMA Negeri 1 Sungailiat kabupaten Bangka?. Tujuan penelitian adalah untuk mengetahui pengaruh model pembelajaran cooperative terpadu terhadap hasil belajar siswa pada mata pelajaran Bahasa Indonesia kelas XI IPS 1 di SMA Negeri 1 Sungailiat.

Populasi penelitian ini adalah seluruh siswa kelas XI di SMA Negeri 1 Sungailiat. Sampel penelitian ini adalah kelas XI IPS 1 sebagai kelas eksperimen dan kelas XI IPS 3 sebagai kelas kontrol. Metode yang digunakan dalam penelitian ini adalah metode eksperimen. Teknik data yang digunakan adalah tes dan teknik wawancara.

Dari hasil perhitungan statistik uji-t dua pihak, diperoleh $=5,91$ dan $=2,000$, dengan taraf $\operatorname{signifikan} \alpha=0,05$. Dengan demikian berarti $>$, maka Ha diterima. Hal tersebut menunjukan adanya pengaruh model pembelajaran cooperative terpadu terhadap hasil belajar siswa pada mata pelajaran Bahasa Indonesia pada materi memahami ide pokok pada teks eksplanasi di kelas XI IPS 1 SMA Negeri 1 Sungailiat kabupaten Bangka.
\end{abstract}

Kata kunci: Cooperative terpadu, ide pokok, teks eksplanasi.

\section{THE EFFECT OF INTEGRATED COOPERATIVE MODEL IN LEARNING UNDERSTANDING THE IDEAS ON EXPLANATION TEXT OF XI IPS 1 CLASS IN SUNGAILIAT 1 STATE HIGH SCHOOL, BANGKA DISTRICT}

\begin{abstract}
Integrated cooperative learning allows each group to work together with other groups, each group presents the results of the discussion and the other groups respect the group who present their learning outcomes. The formulation of the problem in this study is whether there is an influence of integrated cooperative models in learning to understand the main idea in the explanatory text of class XI IPS 1 students at Sungailiat 1 State High School, Bangka district. The purpose of the study was to determine the effect of integrated cooperative learning models on student learning outcomes in Indonesian subjects in class XI IPS 1 at Sungailiat 1 Public High School.

The population of this study were all students of class XI at Sungailiat 1 Public High School. The sample of this study is class XI IPS 1 as the experimental class and class XI IPS 3 as the control class. The method used in this research is the experimental method. Data techniques used are tests and interview techniques.

From the results of the statistical calculation of the two-party t-test, obtained $=5.91$ and $=2,000$, with a significant level of $\alpha=0.05$. Thus means $>$, then $\mathrm{Ha}$ is accepted. This shows the influence of an integrated cooperative learning model on student learning outcomes in Indonesian subjects on the material understanding the main idea in the explanatory text in class XI IPS 1 of SMA Negeri 1 Sungailiat in Bangka district.
\end{abstract}

Keywords: Integrated cooperative, main idea, explanatory text. 


\section{A. PENDAHULUAN}

Pendidikan adalah usaha sadar dan terencana untuk mewujudkan suasana belajar dan proses pembelajaran agar peserta didik secara aktif dapat mengembangkan dirinya untuk memiliki kekuatan spiritual keagamaan, pengendalian diri, kepribadian, kecerdasan, ahlak mulia, serta keterampilan yang diperlukan dirinya, masyarakat, bangsa dan negara.

Kemajuan suatu bangsa tidak terlepas dari faktor pendidikan karena mempunyai peranan penting dalam usaha meningkatkan sumber daya manusia. Peningkatan sumber daya manusia diperoleh melalui pendidikan di sekolah dengan melalui proses pembelajaran, kemajuan suatu bangsa dapat dilihat dari minat baca dari masyarakat itu sendiri. Karena proses membaca merupakan proses yang tidak terlepas dari kehidupan sehari-hari baik dalam masyarakat maupun sekolah.

Salah satu materi pembelajaran dari kompetensi dasar teks eksplanasi adalah memahami teks eksplanasi dengan pemahaman dalam menentukan ide pokok pada teks eksplanasi yang diberikan kepada siswa kelas XI yang menggunakan kurikulum 2013. Kosasih (2014:197) menjelaskan, teks eksplanasi merupakan teks yang menjelaskan proses asal-usul peristiwa alam, sosial dan budaya. Oleh karena itu, teks tersebut banyak menggunakan kata-kata yang merujuk pada pola urutan waktu (kronologis, temporal) teks eksplanasi juga bersifat faktual dengan fokus pada objek yang dijelaskan. Mata pelajaran teks eksplanasi pada kurikulum 2013 yang baru dilaksanakan dan diterapkan disekolah-sekolah, Mulyasa (2014:7) mengemukakan kurikulum 2013 ini merupakan pendidikan karakter dapat diintegrasikan dalam seluruh pembelajaran pada setiap bidang studi yang terdapat dalam kurikulum,

Dalam penelitian ini peneliti menggunakan model cooperative terpadu dengan materi memahami ide pokok pada teks eksplanasi dikarenakan pada materi ini siswa dapat menemukan letak ide pokok yang akan menjadi bahan persoalan yang dikerjakan oleh setiap kelompok siswa, dengan pembahasan materi teks eksplanasi yang sangat berkaitan dengan fenomena yang ada di lingkungan sekitar kita misalnya fonemena terjadinya tsunami, gempa dan lain-lainnya. Materi ini bisa kita temui dalam media masa maupun media tulis. Dengan menggunakan model cooperative terpadu ini siswa dituntut untuk saling berinteraksi, bekerjasama dalam kelompoknya karena model cooperative ini dalam kegiatan belajar dengan membentuk suatu kelompok kecil agar setiap kelompok bisa berbagi wawasan, pengalaman dan pengetahuannya yang berkaitan dengan bahan bacaan teks eksplanasi. Peneliti tertarik untuk melakukan 
penelitian dengan judul "Pengaruh model cooperative terpadu dalam pembelajaran memahami ide pokok pada teks eksplanasi siswa kelas XI IPS 1 di SMA Negeri 1 Sungailiat kabupaten Bangka".

Berdasarkan latar belakang penelitian masalah penelitian di atas, maka masalah yang akan dibahas dalam penelitian ini adalah adakah pengaruh model cooperative terpadu dalam pembelajaran memahami ide pokok pada teks eksplanasi siswa kelas XI IPS 1 di SMA Negeri 1 Sungailiat kabupaten Bangka?

Berdasarkan uraian masalah tujuan penelitian ini adalah untuk mengetahui dan mendeskripsikan hasil penggunaan model cooperative terpadu dalam pembelajaran memahami ide pokok pada teks eksplanasi siswa kelas XI IPS 1 di SMA Negeri 1 Sungailiat kabupaten Bangka.

Hasil penelitian ini diharapkan memberikan manfaat bagi siswa, guru, dan pengajaran bahasa Indonesia.

- Bagi siswa, hasil penelitian ini diharapkan dapat memberikan masukan untuk lebih memahami proses pembelajaran memahami ide pokok pada teks eksplanasi.

- Bagi guru, hasil penelitian ini diharapkan dapat memberikan masukan sebagai upaya menerapkan model cooperative terpadu dalam pelajaran memahami ide pokok pada teks eksplanasi.

- Bagi pengajaran Bahasa Indonesia, hasil penelitian ini diharapkan dapat memberikan kontribusi dalam meningkatkan pencapaian tujuan pembelajaran sesuai dengan kompetensi dasar membaca.

Definisi operasional adalah definisi yang dirumuskan oleh peneliti tentang istilah-istilah yang ada pada masalah peneliti. Jadi sesuai dengan definisi operasional saya antara lain :

- Pengaruh merupakan daya yang ada atau timbul dari sesuatu. Sedangkan pembelajaran menurut Rusman (2014:134) mengemukakan suatu proses interaksi antara guru dengan siswa, baik interkasi secaraa langsung seperti kegiatan tatap muka maupun secara tidak langsung, yaitu dengan menggunakan berbagai media pembelajaran.

- Rusman (2014:132) Model pembelajaran adalah suatu kegiatan pembelajaran yang harus dikerjakan guru dan siswa agar tujuan pembelajaran dapat dicapai secara efektif dan efisien". 
- Rusman (2014:202) mengemukakan, model cooperative terpadu adalah teknik pengelompokan yang di dalamnya siswa bekerja searah pada tujuan belajar bersama dalam kelompok kecil.

- Menurut Kosasih (2014:197),"Teks eksplanasi merupakan teks yang menjelaskan proses atau asal-usul peristiwa alam, sosial, atau budaya". Oleh karena itu, teks tersebut banyak menggunakan kata-kata yang merujuk pada pola urutan waktu (kronologis, temporal) dan kausallitas.

- Kosasih (2014:1) mengemukakan,’Paragraf adalah rangkaian kalimat yang saling berhubungan dan membentuk satu kesatuan pokok pembahasan.

- Kosasih (2014:1) mengemukakan, "Gagasan utama merupakan gagasan yang menjadi dasar pengembangan suatu paragraf".

- Kosasih (2014:6) mengemukakan,’Terdapat empat cara menempatkan ide pokok paragraf atau pokok gagasannya, yaitu : (1) pada paragraf deduktif, (2) pada paragraf induktif, (3) pada paragraf campuran (deduktif-induktif), (4) pada paragraf deskriptif/naratif (pada seluruh kalimat).

Arikunto (2014:104) mengemukakan,"Anggapan dasar atau postulat adalah sebuah titik tolak pemikiran yang kebenarannya diterima oleh penyelidik". Anggapan dasar dalam penelitian ini adalah sebagai berikut:

- Dalam Kurikulum 2013 untuk Sekolah Menengah Atas (SMA) terdapat pembelajaran tentang memahami teks eksplanasi.

- Siswa kelas XI IPS 1 SMA Negeri 1 Sungailiat kabupaten Bangka sudah mempelajari materi pembelajaran tentang memahami ide pokok pada teks

Hipotesis adalah dugaan sementara dari suatu masalah yang akan diuji kembali kebenarannya dengan signifikan. Pada penelitian ini, peneliti mengajukan hipotesis bahwa dengan pembelajaran model cooperative terpadu terdapat pengaruh hasil belajar siswa pada mata pelajaran memahami ide pokok pada teks eksplanasi siswa kelas XI IPS 1 di SMA Negeri 1 Sungailiat kabupaten Bangka.

Kriteria penguji hipotesis yang digunakan adalah:

- Ho terima jika $\leq$ : tidak ada pengaruh yang signifikan penggunaan cooperative terpadu terhadap hasil belajar pada materi memahami ide pokok pada teks eksplanasi siswa kelas XI IPS 1 di SMA Negeri 1 Sungailiat kabupaten Bangka. 
- Ha diterima jika $\geq$ : ada pengaruh yang signifikan penggunaan cooperative terpadu terhadap hasil belajar pada materi memahami ide pokok pada teks eksplanasi siswa kelas XI IPS 1 di SMA Negeri 1 Sungailiat kabupaten Bangka.

\section{B. METODE PENELITIAN}

Metode penelitian adalah cara yang digunakan oleh peneliti dalam mengumpulkan data penelitiannya". Berdasarkan pendapat tersebut, maka penelitian menggunakan metode eksperimen kuantitatif. Sedangkan jenis eksperimen peneliti menggunakan pendekatan true experimental design (Sugiyono 2015:112). peneliti memilih bentuk Posttest Only Control Design yaitu terdapat dua kelompok yang masing-masing dipilih secara random (R). kelompok pertama diberikan perlakukan (X) dan kelompok yang lain tidak.

\section{HASIL PENELITIAN DAN PEMBAHASAN}

Hasil penelitian pada kedua sampel kelas eksperimen yang menggunakan model cooperative terpadu mendapatkan nilai rata-rata 78,40 dan di kelas kontrol yang hanya menggunakan metode ceramah mendapatkan nilai 65,38 .

Pada pengujian hasil uji normalitas nilai modus pada kelas eksperimen terdapat pada nilai 85-90 dengan jumlah 16.

- Menghitung nilai modus dengan menggunakan rumus:

$$
\begin{aligned}
& \mathrm{b}=(85-0,5=84,5) \\
& \mathrm{p}=6 \\
& \mathrm{~b} 1=16-0=16 \\
& \mathrm{~b} 2=16-0=16 \\
& =\mathrm{b}+\mathrm{p} \\
& =84,5+6 \\
& =84,5+6() \\
& =84,5+6+(0,5) \\
& =84,5+6,5 \\
& =91
\end{aligned}
$$


- Menentukan kemiringan (KM) dengan menggunakan rumus:

$$
\begin{aligned}
\mathrm{KM} & = \\
& ==-1,24
\end{aligned}
$$

Hasil kemiringan yang didapat adalah $=-1,24$

Dikatakan normal apabila nilai KM berada diantara -1 dan +1

Dan nilai modus pada kelas kontrol terdapat pada nilai 55-59 dengan jumlah 12

- Menghitung nilai modus dengan menggunakan rumus:

$$
\begin{aligned}
& \mathrm{b}=(55-0,5=54,5) \\
& \mathrm{p}=5 \\
& \mathrm{~b} 1=12-0=12 \\
& \mathrm{~b} 2=12-7=5 \\
& =\mathrm{b}+\mathrm{p} \\
& =54,5+5 \\
& =54,5+5() \\
& =54,5+5(0,70) \\
& =54,5+3,5 \\
& =58
\end{aligned}
$$

- Menentukan kemiringan (KM) dengan menggunakan rumus:

$$
\begin{aligned}
\mathrm{KM} & = \\
& ===0,82
\end{aligned}
$$

Hasil kemiringan yang didapat adalah $=0,82$

Dikatakan normal apabila nilai KM berada diantara -1 dan +1

Berdasarkan data yang diperoleh maka mendapatkan nilai uji homogenitas:

$\mathrm{F}===1,26$

$=1,26$

Dari kedua harga $\mathrm{F}$ diperoleh jelas terlihat bahwa $\leq$. Dengan demikian dapat disimpulkan bahwa varians dalam penelitian ini homogen.

Setelah dilakukan uji normalitas dan uji homogenitas, maka telah memenuhi syarat untuk menganalisis data menggunakan rumus statistik t-tes dua pihak dengan pengujian hipotesis penelitian yang mendapatkan nilai 9,55 
Berdasarkan hasil pengujian hipotesis dengan menggunakan rumus uji-t, diperoleh $=5,91$. Analisis data uji $\mathrm{t}$ dua pihak dengan taraf signifikan $\alpha=0,05 \mathrm{dan} \mathrm{d} k(+-2)=60$ diperoleh hasil $=$ 5,91 dan $=2,000$. Dengan demikian berarti $\geq$ sehingga Ho ditolak dan Ha diterima.

Penelitian ini dilakukan pada 2 kelas sampel, dimana dalam penelitian sampel menggunakan teknik Cluster sampling dalam teknik ini, random dilakukan atas dasar himpunan atau kelompok dengan tanpa mempertimbangkan besar atau kecilnya jumlah anggota sebuah himpunan atau kelompok, dimana kelas XI IPS 1 menjadi kelas eksperimen dan kelas XI IPS 3 menjadi kelas kontrol. Yang menjadi kelas eksperimen diajarkan menggunakan model pembelajaran cooperative terpadu dan sebagai kelas kontrol yang hanya diajarkan dengan menggunakan metode ceramah. Metode penelitian yang digunakan dalam penelitian ini adalah metode eksperimen. Sedangkan jenis eksperimen peneliti menggunakan true experimental design dengan bentuk posttest only control design. Pemilihan penggunaan metode tersebut bertujuan untuk melihat pengaruh hasil belajar siswa pada kelas sampel. Peneliti mengharapkan adanya perbedaan antara hasil belajar siswa kelas eksperimen dengan siswa kelas kontrol.

Dari hasil dari pembelajaran menggunakan model cooperative terpadu ini di kelas XI IPS 1 sebagai kelas eksperimen dapat dikatakan bahwa sebagian besar siswa dapat menerapkan pembelajaran cooperative terpadu dalam kegiatan pembelajarannya, hal ini terbukti dari rata-rata post-test yang di dapatkan siswa yaitu 78,40 sedangkan rata-rata hasil belajar siswa kelas XI IPS 3 sebagai kelas kontrol yaitu 65,38.

Kemudian pada tahap menetapkan hipotesis peneliti memberi kesempatan pada siswa untuk mendiskusi materi yang telah ditentukan. Selanjutnya secara berkelompok siswa mendiskusikan permasalahan tersebut. Pada tahap siswa mencari informasi, data, fakta yang diperlukan untuk menjawab permasalahan/hipotesis peneliti membimbing siswa untuk menarik kesimpulan jawaban atau generalisasi peneliti memilih satu kelompok untuk mempresentasikan hasil diskusinya, setelah mempresentasikan hasil kegiatan belajar, peneliti menjelaskan sedikit tentang materi tersebut. Pada kegiatan penutup peneliti bersama siswa menyimpulkan materi yang telah dipelajari dan mengingatkan kepada siswa untuk mempelajari materi yang akan dipelajari selanjutnya.

Peneliti ini bertujuan untuk mengetahui hasil belajar siswa dengan menggunakan model pembelajaran cooperative terpadu terhadap hasil belajar siswa pada mata pelajaran Bahasa Indonesia kelas XI IPS 1 di SMA Negeri 1 Sungailiat kabupaten Bangka. Berdasarkan analisis 
data hasil tes kelas eksperimen yang menggunakan model pembelajaran cooperative terpadu dapat diketahui bahwa nilai rata-rata nilai post-test siswa kelas eksperimen yaitu kelas XI IPS 1 sebesar 78,40 dimana nilai tertingginya adalah 90 yang dapat diperoleh 3 orang siswa dan nilai terendahnya adalah 55 yang didapat oleh 2 orang siswa, sedangkan untuk kelas XI IPS 3 sebagai kelas kontrol yang tidak menggunakan menggunakan model pembelajaran cooperative terpadu dapat diketahui bahwa nilai rata-rata post-test siswa sebesar 65,38 di mana nilai tertingginya adalah 80 yang didapat oleh 3 orang siswa dan nilai terendahnya adalah 55 yang didapat oleh 13 orang siswa. Hal tersebut menunjukan bahwa hasil belajar siswa dengan pembelajaran menggunakan model cooperative terpadu lebih baik daripada hasil belajar siswa yang menggunakan metode ceramah.

Selain itu dari pengujian normalitas data yang dilakukan, tampak bahwa kedua kelas tersebut normal karena didapat dari perhitungan untuk kelas eksperimen sebesar -1,24 (Negatif) berarti terletak diantara (-1) dan (+1) maka data tersebut berdistribusi normal dan untuk kelas kontrol 0,82. Kedua kelas tersebut memilik nilai normal karena $\mathrm{KM}$ terletak antara -1 dan +1 dalam selang $(-1<\mathrm{KM}<+1)$. Setelah kedua kelas tersebut berdistribusi normal, maka dapat dilanjutkan ke uji homogenitas. Uji homogenitas perlu dilaksanakan untuk membuktikan kesamaan varians kelompok yang dibentuk oleh sampel tersebut yang sama. Untuk mencari homogenitas data dalam penelitian ini menggunakan uji F. dengan syarat homogen 1 maka data tersebut homogen.

Sebelum mengetahui homogen atau tidaknya suatu data, harus diketahui dulu varians kelas eksperimen varians kelas kontrol . Berdasarkan hasil dari dapat yang di peroleh peneliti varians kelas eksperimen 101,92 dan varians kelas kontrol $=80,64$ dan nilai untuk $=1,26$ dan $=1,84$, $\leq$ berarti data tersebut homogen. Setelah data dari masing-masing sampel terbukti berdistribusi normal, dan homogen, maka data tersebut dapat dioleh dengan uji statistik yaitu dengan uji t dua pihak. dari hasil perhitungan uji t dengan taraf signifikan $\alpha=0,05$, diperoleh $=5,91=2,000$. Dengan demikian berarti $\geq$, maka Ho ditolak dan Ha diterima.

Hal tersebut menunjukan adanya pengaruh model pembelajaran cooperative terpadu terhadap hasil belajar siswa pada materi memahami ide pokok pada teks eksplanasi khususnya pada mata pelajaran Bahasa Indonesia di kelas XI IPS 1 di SMA Negeri 1 Sungailiat kabupaten Bangka. 


\section{SIMPULAN DAN SARAN}

Berdasarkan hasil penelitian dan pembahasan yang telah dikemukakan, maka dapat disimpulkan sebagai berikut:

- Ada pengaruh model pembelajaran cooperative terpadu terhadap hasil belajar siswa kelas XI IPS 1 di SMA Negeri 1 Sungailiat pada mata pelajaran memahami ide pokok pada teks eksplanasi.

- Berdasarkan hasil tes didapat nilai rata-rata siswa untuk kelas eksperimen setelah menggunakan model pembelajaran cooperative terpadu adalah 78,40 dan nilai rata-rata tes siswa kelas kontrol yang diajarkan dengan metode ceramah adalah 65,38 hal tersebut menunjukan bahwa variasi mengajar dapat meningkatkan hasil belajar siswa.

Berdasarkan kesimpulan di atas, maka peneliti menyatakan saran sebagai berikut:

- Bagi siswa, model pembelajaran cooperative terpadu siswa dapat digunakan untuk meningkatkan motivasi belajar.

- Bagi guru, model pembelajaran cooperative terpadu dapat digunakan dalam meningkatkan hasil belajar siswa.

- Bagi peneliti, model pembelajaran cooperative terpadu dapat menjadi bahan untuk penelitian lebih lanjut.

\section{DAFTAR PUSTAKA}

Arikunto, Suharsimi. 2014. Prosedur Penelitian. Jakarta: PT Rineka Cipta.

Kosasih, Engkos. 2014. Cerdas Berbahasa Indonesia. Jakarta: Erlangga.

Kosasih, E. 2014. Dasar - Dasar Keterampilan Menulis. Bandung: CV Yrama Widya.

Mulyasa, E. 2014. Pengembangan dan Implementasi Kurikulum 2013. Bandung: PT Remaja Rosdakarya.

Rusman. 2014. Model-Model Pembelajaran. Jakarta: Rajawali Pers.

Sugiyono. 2015. Metode Penelitian Pendidikan. Bandung: Alfabeta. 